\title{
Distanciamiento social, infodemia, desinformación y noticias falsas: Invitados invisibles en pandemia
}

Social Distancing, Infodemic, Misinformation and Fake

News: Invisible Guests in a Pandemic

Recepción: 31/01/2021, revisión: 04/03/2021, aceptación: 08/03/2021, publicación: septiembre de 2021

https://revistas.uasb.edu.ec/index.php/uru

(D) María Isabel Calle León

icalle@consejodecomunicacion.gob.ec

Consejo de Regulación, Desarrollo y Promoción de la Información y Comunicación (Quito, Ecuador)

https://orcid.org/0000-0002-8202-1977

(ID) Roberto Sánchez Cazar

jsanchez@consejodecomunicacion.gob.ec

Consejo de Regulación, Desarrollo y Promoción de la Información y Comunicación (Quito, Ecuador)

https://orcid.org/0000-0003-1517-2836

(ID) Carlos W. Vizuete C.

cvizuete@consejodecomunicacion.gob.ec

Consejo de Regulación, Desarrollo y Promoción de la Información y Comunicación (Quito, Ecuador)

https://orcid.org/0000-0002-0073-8027

DOI https://doi.org/10.32719/26312514.2021.4.2

\section{Resumen}

La proliferación de noticias falsas en Ecuador, durante el período de confinamiento generado por la pandemia relacionada con el COVID-19, evidenció las diversas dimensiones de este fenómeno. Este artículo analiza las principales categorías involucradas en la generación y proliferación de noticias falsas con el fin de propender a un entendimiento y posterior debate que aporte a la generación de estrategias para la prevención e incluso reducción de su impacto.

\section{Abstract}

The proliferation of fake news in the confinement period generated by the pandemic related to Covid-19, in Ecuador show the various dimensions of this phenomenon. This article analyzes the main categories involved in the generation and proliferation of fake news in order to promote an understanding and subsequent debate that contributes to the creation of strategies for the prevention and also reduction of its impact.

\section{Palabras clave $\cdot$ Keywords}

Noticias falsas, desinformación, infodemia, medios de comunicación, plataformas digitales. Fake news, misinformation, infodemia, mass media, digital platforms. 
Marzo de 2020 bien puede ser declarado como el mes que evidenció un antes y un después a nivel mundial en todos los aspectos conocidos por las sociedades, a causa del inicio de la pandemia ocasionada por el COVID-19.

Los sistemas de información y comunicación no estuvieron exentos de estos cambios. Es más, el ambiente comunicacional fue el que mayor transformación presentó, y puso en evidencia la pregnancia e importancia de los procesos comunicacionales en medio de una emergencia sanitaria, y cómo la falta de preparación y prolijidad en el manejo comunicacional pueden desencadenar en pánico y desesperanza al interior de la sociedad.

En el año 2018, la Organización Panamericana de la Salud (OPS) se refería al fenómeno de las noticias falsas (fake news) desde la perspectiva de la movilización y manipulación de la información, que ha sido una característica histórica aun antes de que el periodismo moderno estableciera estándares que definen a la noticia como un género basado en reglas particulares de integridad (OPS 2021).

Asimismo, en referencia a la infodemia, la Organización Mundial de la Salud (OMS) la define como la epidemia nociva de rumores que se generan durante brotes y enfermedades de carácter masivo. Esa definición permite descartar una de las acepciones que se suelen usar en el registro coloquial cuando se habla de infodemia, y que solo atiende a la sobreabundancia de información y de datos (Becerra, en EC Consejo de Regulación, Desarrollo y Promoción de la Información y Comunicación [CRDPIC] 2020b).

Por su parte, el informe de la Relatoría de Libertad de Expresión de la Comisión Interamericana de Derechos Humanos (CIDH 2019) se refiere a la desinformación como "la difusión masiva de información falsa que tenga la intención de engañar al público y sea producida y distribuida a sabiendas de su falsedad" (EC CRDPIC 2020b). A diferencia de las llamadas noticias falsas (fake news), de cuya falsedad no tenga plena conciencia quien las distribuye, la desinformación tiene una intención deliberada de causar daño.

$\mathrm{Al}$ inicio de la pandemia, el país fue escenario de la proliferación y difusión de fake news, a tal punto que, por ejemplo, hasta el lunes 23 de marzo de 2020, en los primeros doce días de la emergencia sanitaria, las noticias falsas difundidas en Ecuador tuvieron más de 40 millones de impactos; el $50 \%$ de ellas fue generado desde México. Esto no quiere decir que hubo ese número de noticias falsas, sino que se las vio esa cantidad de veces (Primicias 2020).

El escenario de producción y viralización de noticias falsas en el contexto de pandemia puso en evidencia la gravedad de estos fenómenos y sus consecuencias perjudiciales. Es así que el CRDPIC organizó una serie de foros y encuentros virtuales con expertos nacionales e internacionales provenientes de la academia y de los medios de comunicación, en una suerte de exposiciones magistrales, para exponer distintas perspectivas sobre el tratamiento de la información y el combate a las noticias falsas y la desinformación. 
De esta forma, el presente trabajo tiene como base la interpretación y sistematización de criterios y conceptos de expertos en materia de comunicación, a partir de las memorias de los encuentros virtuales.

\section{Metodología}

Los encuentros que realiza el CRDPIC tienen por objeto poner en valor el diálogo y la exposición de diversos temas en torno al quehacer periodístico y comunicacional, a través de la participación de expertos académicos y profesionales de la comunicación, quienes presentan distintos puntos de vista y provocan espacios de reflexión y debate para la construcción de nuevas dinámicas comunicacionales y periodísticas, en el marco de la libertad de expresión y la protección de derechos, en beneficio de la ciudadanía.

Los insumos que sirvieron de base, y que se despliegan a lo largo del presente trabajo, forman parte de las memorias de foros virtuales realizados entre los meses de abril y mayo de 2020, que se detallan a continuación: 1) "Infodemia: Desinformación en crisis sanitaria”, que contó con la participación de expertos tanto de la academia como de los medios de comunicación: Verónica Yépez, Jaime Breihl, Carmen Andrade y Christian Espinosa; 2) "Desinformación viral: Las noticias en la pandemia", que contó con la conferencia magistral de Martín Becerra; 3) "Ciberespacio, desinformación y periodismo activo", con la ponencia de Arturo Torres; 4) "Ciclo de conferencias: Innovación de modelos de negocio para medios de comunicación”, con la participación de Eduardo Torres Carmagnola, Isabela Ponce, Albertina Navas y José Luis Orihuela; y 5) "Ciclo virtual: Seguridad para periodistas en situaciones de riesgo", con las ponencias de expositores nacionales e internacionales: Gisella Bayona, Martí Quintana Badosa, Pedro Vaca Villareal, Susana Morán, Jennifer Bolaños, Gustavo Valencia, Dayana Monroy y Eric Samson.

Asimismo, se incluyen referencias teóricas y prácticas desde las diversas organizaciones mundiales, que aportan tanto al entendimiento de los diferentes conceptos relacionados con las temáticas, así como desde otros documentos nacionales e internacionales que permiten identificar el contexto en el cual se desarrollan las noticias falsas y la desinformación. De esta manera, la revisión bibliográfica y la contrastación con los criterios vertidos por los participantes en los encuentros generan los acercamientos teóricos a las temáticas y son la base de este artículo.

\section{Análisis y resultados}

"El periodismo ya no solo informa, relata la realidad y en muchos sentidos la define, la crea: [...] la remediación es una reforma en el sentido de que los medios reforman la realidad misma. No es que los medios de comunicación simplemente reforman la apariencia de la realidad" (Bolter y Grusin 2000, 61). Ahora bien, esa creación no es unívoca, es decir, no es una invención de los medios, sino que es una representación de la realidad. 
El hecho comunicacional literalmente vuelve a presentar la realidad, la representa, insiste sobre ella y le da una lectura, un sesgo. Por lo mismo, el análisis que se pueda hacer de la actividad informativa tiene que atender a contextos más amplios que los propios medios, porque estos son expresión o representación de esas realidades, no fuentes unilaterales de sentido.

En la otra orilla parecería estar el otro periodismo, más pausado y que necesita un tiempo para ser producido, un tiempo que los medios no pueden darse el lujo de tener y que termina jugando en contra de la propia intención informativa. "El periodismo permite que una sociedad permanezca unida, que no reaccione desde lo emocional, sobre todo en contextos de crisis en que la ciudadanía necesita información fidedigna" (EC CRDPIC 2020d), función que se ha visto muy limitada en los medios de comunicación.

Acorde a lo que publica el informe "Panorama de los medios en el Ecuador",

la reputación de los periodistas en Ecuador no es particularmente buena. El 46,85 \% de la población los considera corruptos, y apenas un poco más, el 49,95\%, los califica de fiables. En términos generales, un 51,74 \% de la población considera a los medios de comunicación corruptos y solamente el $45,35 \%$ de la población los percibe como fiables. (Gehrke et al. 2016, 6)

A esto se suma la polarización que desde 2010 evidenció de diversas formas la organización Reporteros sin Fronteras. Esta tenía un particular contexto para 2016, a partir del cuestionamiento público que desde los ámbitos gobernantes se hacía a la fiabilidad de las empresas de medios privados (Gehrke et al. 2016), al confrontarlos con la propia ética del ejercicio periodístico, lo que provocó una reacción corporativa que creó la inevitable polarización que Reporteros sin Fronteras evidencia en la cita.

$\mathrm{Al}$ respecto, el informe conjunto del relator especial para la libertad de expresión de la Comisión Interamericana de Derechos Humanos (CIDH), Edison Lanza, y del relator especial de las Naciones Unidas sobre la promoción y protección del derecho a la libertad de opinión y de expresión, David Kaye, en junio de 2019, determina que, en el contexto ecuatoriano, las prácticas que se dieron en el Gobierno de Rafael Correa crearon mucha desconfianza hacia los periodistas y pusieron en duda la existencia de una prensa libre e independiente (CIDH 2019).

Según la encuestadora Perfiles de Opinión, la credibilidad de los grandes medios se ubica, a enero de 2020 , en apenas el $20 \%$, fenómeno que tiene que ver con las movilizaciones de octubre de 2020, durante las cuales un $86 \%$ de la población consideró que los grandes medios ocultaron la verdad (Confirmado 2019).

A esta percepción hay que sumarle la caída del rating de los noticieros, como corrobora María Dolores Mosquera, gerente de la Agencia Publi Point, quien considera que son preocupantes la situación de la publicidad televisiva, la reducción del número de ejemplares impresos por los principales diarios del país ${ }^{1}$ y el terreno perdido por los grandes 
medios en relación al aumento de los medios digitales, que además se ha potenciado durante la emergencia sanitaria.

Los avances tecnológicos generados a partir de las últimas décadas han permitido que en la actualidad la consulta de información ya no se realice únicamente a través de la prensa escrita, la radio y la televisión, sino que se acuda a otros medios, como las redes sociales y los espacios virtuales. Estas herramientas se han convertido en las favoritas para la consulta de información entre las generaciones más jóvenes, cuya naturaleza digital es indiscutible (Casero-Ripollés 2012). A esta transformación se une el avance experimentado, en este aspecto, por el servicio de mensajería instantánea de WhatsApp (Newman et al. 2017).

Vivimos en un mundo interconectado en el cual la comunicación es "un modo de producir sentido social, de afirmar o transformar percepciones y representaciones, de conectar con promesas de futuro y de buscar las formas narrativas del mundo" (Rincón 2013, 13). Al mismo tiempo, los medios de comunicación tanto tradicionales (prensa escrita, radio y televisión) como digitales se han convertido en "un poder importante en el espacio individual, familiar y social; mediadores [...] que canalizan y crean opinión pública (elemento decisivo en el proceso de elaboración de las políticas públicas); instrumentos de cultura y vehículos de difusión de obras culturales" (Freidenberg 2004, 1).

En este contexto, la información se ha vuelto un recurso necesario para las sociedades contemporáneas, lo que ha provocado el "aumento de información, pero también la desinformación y la propagación de noticias falsas, sin documentar, con autoría anónima, interesada o incluso maliciosa" (Catalina-García, Sousa y Silva 2019, 94). Una noticia es objetiva cuando tiene dos características: factualidad e imparcialidad.

La factualidad está relacionada con los hechos, con la veracidad y relevancia de lo contado, mientras que la imparcialidad hace referencia a la equidad en el relato y a la presentación neutral de las noticias. A su vez, enfatiza, la factualidad está definida por la veracidad y la relevancia (Burgos 2019, 8).

La veracidad tiene que ver con la capacidad de asociar los hechos con la fiabilidad y credibilidad de lo acontecido. Para ello se evalúa a los hechos con los tres atributos principales de la información: facticidad, exactitud y completitud. La facticidad tiene que ver con que la información se va a referir a lo verdaderamente sucedido, y no a las opiniones de lo que ocurrió. Por eso, el método objetivo en el periodismo insistirá en basarse en fuentes y testimonios de lo sucedido, para blindar a las noticias de influencias de terceros en su construcción (8).

\footnotetext{
${ }^{1}$ La impresión de ejemplares diarios (conocida como tiraje) cayó en un 50 \% desde el año 2010 (Pichincha Comunicaciones 2020).
} 
Para poder entender el fenómeno de las fake news y su incidencia, es necesario señalar la función "comercial" de la producción de la noticia o de los contenidos. Así, siendo que la representación es un montaje, una puesta en escena, la objetividad se vuelve inmanejable, más aún cuando existen intereses de por medio. Pedro Vaca, al plantear las características propias del ejercicio investigativo, resalta que el periodismo de investigación debe tener exactitud y no caer en una doble agenda, debe ser ecuánime y exponer el punto de vista de todos los implicados (EC CRDPIC 2020e). Además, coloca sobre la mesa los puntos que dotan de legitimidad a una denuncia periodística cuando se hace con las pruebas necesarias y la contratación de fuentes, es decir, aquellos principios básicos del ejercicio periodístico que necesitan mantenerse más allá del soporte en que se difunda un contenido.

Por lo tanto, la objetividad, entendida como neutralidad, toma otra dimensión: es reemplazada por la contrastación, por la inteligencia que se pueda hacer de un dato para darle contexto y profundidad y permitir que la audiencia deje de ser tratada como consumidora para ser tratada como tal, como audiencia.

En este sentido, la difusión de noticias que no tomen en cuenta estas características puede reproducir fake news y, con ello, atentar contra los derechos de la información y comunicación.

En este contexto entra en juego el papel que deben desempeñar los profesionales de la Comunicación, que deben seguir manteniendo su estatus de autoría reconocida, aunque en la práctica se está viendo que basan algunas de sus informaciones en contenidos que les llegan desde los medios digitales sin entablar una relación directa con la fuente. (Catalina-García, Sousa y Silva 2019, 94)

Por lo tanto, la relación entre posverdad y desinformación también afecta al trabajo de los comunicadores. La posverdad, palabra frecuentemente utilizada en el argot comunicacional de los últimos tiempos, "tiene un marco de referencia más amplio que las fake news" (Murolo 2019, 5). Una de las características de la posverdad es que se la considera como un paraguas más amplio que las noticias aisladas; además, es condición de posibilidad para que existan fake news (Britos y Auzoberría 2019). De ahí que

la posverdad no solamente es mentira, sino que se construye con fake news de las cuales no importa su falsedad porque operan como reafirmación de aquello que las audiencias previamente han incorporado como verdadero. Operan más en el plano emocional que en lo racional, tienen sustento más en los sentimientos construidos previamente que en hechos contrastables. Tanto la posverdad a modo imaginario, como las fake news que la sustentan, deben estar construidas bajo el rigor de la verosimilitud. No es una verdad filosófica, ni de una realidad chequeable, sino de una posibilidad de ser. No se asientan en la lógica disparatada del meme ni del sarcasmo del gif, sino en la estructura probada de los géneros periodísticos y de la reiteración mediática. (Murolo 2019, 68) 
Para Amorós, la posverdad define la circunstancia en la que los hechos objetivos son menos influyentes en la opinión pública que las emociones y las creencias personales. Pero “¿cómo se logra esto? A través de las fake news. Es decir, con la circulación de noticias falsas que se potencian a través de internet y las redes sociales, 'recreando' una opinión pública" $(2019,183-4)$.

La posverdad, por lo tanto, ha facilitado que la sociedad de la información se convierta en una sociedad de la desinformación o de la información falsa, en la que las fake news no se crean por diversión, sino para obtener un beneficio. Y este puede que sea económico, político o ideológico (Britos y Auzoberría 2019, 6). Por lo tanto, "se trata de informaciones falsas diseñadas para hacerse pasar por noticias con el objetivo de difundir un engaño o una desinformación deliberada para obtener un fin político o financiero" (Amorós 2019, 29).

Desde ese punto de vista, el término posverdad no significa que algo sea falso, sino que alude a

un estado de confusión e incertidumbre en el que los conceptos de "verdad" y "mentira" han sido ya neutralizados. Porque, cuando predomina la sensación de que nada es comprobable, se impone un escepticismo general que impide hablar de hechos verdaderos o falsos. (Mayoral, Parratt y Morata 2019, 396)

En este juego, las estrategias de desinformación ganan cuando los periodistas y la ciudadanía no disponen de mecanismos ni de herramientas de comprobación para cada discurso o enunciado, por ello la importancia del "fact checking (o verificación de hechos) como herramienta para combatir la desinformación" (396).

Cabe agregar que la posverdad "se refiere a las circunstancias en que los hechos objetivos son menos importantes a la hora de modelar la opinión pública que las apelaciones a la emoción o a las creencias personales" (International Federation of Journalists [IFJ] $2018,1)$. También este término hace alusión de forma general "a diferentes fenómenos que se vienen dando en la arena política y mediática desde hace más de tres décadas, poniendo en jaque las democracias occidentales" (Tusa y Durán 2019, 25)

La desinformación no es un virus creado por internet, sino es un rasgo inherente a los sistemas organizados de producción y difusión de contenidos; o sea, es un problema inherente al tipo de sistema de producción de la información en el mundo entero. (EC CRDPIC 2020b)

Estos contenidos generan principalmente desinformación, pues se caracterizan por ser inexactos; propagan rumores no comprobados; varios de ellos buscan hacer daño con el fin de obtener beneficios particulares; afectan a la democracia y a las percepciones que las personas se forman sobre su entorno. Por ende, deben analizarse tomando en cuenta sus dimensiones o implicaciones política, social y cultural (IFJ 2018).

La desinformación, a más de referir el hecho de dar información intencionalmente manipulada al servicio de ciertos fines, conlleva dar información insuficiente u omitirla, 
con el consecuente daño sobre las personas que se encuentran frente al desconocimiento, la ignorancia y la confusión (EC CRDPIC 2020a).

Para Martín Becerra, el fenómeno de la desinformación no es nuevo; sin embargo, en la actualidad ha cobrado fuerza:

No hay períodos exentos de la producción de noticias falsas y de campañas de desinformación. Aunque esté presente, tiene un condimento singular porque existen elementos singulares: la precariedad económica de la actual etapa del ecosistema de comunicaciones, sumada a la multiplicación de plataformas digitales, en las que los propios medios diseminan sus contenidos. Esto vuelve todavía más vulnerable el proceso de edición, de verificación, de cuidado, de curaduría de las noticias, y por lo tanto los resultados son muchos yerros, muchas informaciones adulteradas que se detectan y se padecen a diario. (EC CRDPIC 2020b)

La desinformación ha cobrado impacto con los años: "En 2017 la manipulación por redes se identificó en 28 países, incluido Ecuador; en 2018 afectó a 48 naciones y actualmente a más de 70". También se señala que, en 2019, dentro de los principales actores de desinformación se evidencian partidos políticos, gobiernos y movimientos políticos (EC CRDPIC 2020c).

Sin embargo, como explica Martín Becerra, plantear que solo las plataformas digitales son propagadoras de rumores es una cortina que separa a los medios tradicionales de su participación activa en operaciones de desinformación: "Hay una relación íntima entre medios, conductores, periodistas y servicios de inteligencia; lo que quiere decir que las plataformas digitales pueden ser vehículos de desinformación y rumores, pero no están eximiendo a las instituciones mediáticas y a la política profesional" (EC CRDPIC 2020b).

La desinformación se explica en gran parte porque existe una migración hacia medios digitales, y diversos políticos y actores de diferentes grupos "han visto en las redes una mina de oro para divulgar información sin ningún tipo de filtro o de auditoría o de verificación [en contraste con] una información divulgada por un medio serio" (EC CRDPIC 2020c).

La desinformación puede ser confundida con las fake news, pero es algo mucho "más sutil y con un riesgo colectivo mayor, es un concepto más complejo que la mentira o la inexactitud, puesto que no es casual sino creada con una intención, e incluso en su deformación es un fenómeno informativo" (Del Fresno 2018, 3).

Las redes sociales son las principales fuentes noticiosas de un número creciente de personas, han consolidado la desinformación con mucha fuerza. Se habla de dos motivaciones que hacen que las noticias falsas se propaguen: las económicas y las ideológicas. Las primeras, mediante noticias escandalosas y falsas que se viralizan y generan ganancias publicitarias, con lo que se convierten en una fuente comercial; las segundas buscan desacreditar a los contendores a través de la promoción de ideas que llegan a viralizarse y a ser compartidas por gran cantidad de personas (EC CRDPIC 2020a). 
Es importante acotar que la construcción de las noticias falsas utiliza un fuerte componente emocional, y para ello los recursos visuales están a la orden del día, ya que producen sensaciones que la gente está acostumbrada a procesar rápidamente. Inclusive la evolución de los programas informáticos permite la manipulación de imágenes y videos, con lo que se dificulta la diferenciación entre lo real y lo ficticio y complica aún más la veracidad de una pieza comunicacional que circula en plataformas digitales (EC CRDPIC 2020a).

Las personas tienden a compartir aquello que se adecúa a su forma de pensar, de sentir, a sus ideas y convicciones. En este aspecto, la desinformación se presenta en una inconmensurable cantidad de información que hace que los individuos se inclinen hacia aquello que les es común, y que sea muy poco probable investigar sobre aquello que les es ajeno (Yépez, en EC CRDPIC 2020a).

"Las noticias falsas lo que buscan es básicamente, por un lado, desprestigiar o generar un sentimiento, una sensación en la población para agravar una crisis" (EC CRDPIC 2020c). Además, el autor ejemplifica: en octubre de 2019, en el país se exacerbó una serie de desinformaciones, de campañas que buscaban empeorar aquella coyuntura. Estas se dan sobre todo en redes, utilizadas por distintos grupos, de varias ideologías, para generar noticias falsas y con ellas una serie de ataques. Asimismo, Torres menciona que, en el contexto de la pandemia, se ha identificado "un patrón muy similar en la divulgación de este tipo de información, que, indistintamente de donde provenga, genera en la población y en la sociedad mucho desconcierto, zozobra, miedo. Se exacerban todo tipo de sentimientos y de emociones que básicamente son negativos" (EC CRDPIC 2020c).

La Organización Mundial de la Salud señaló a la desinformación como un virus, y definió a la infodemia como la difusión descontrolada y rápida de información falsa a través de redes, que llega por medio de memes y mal llamadas "noticias" que alimentan creencias sesgadas, incrementan las controversias y crean estados de confusión, incertidumbre y ansiedad (EC CRDPIC 2020a).

Dos ejes fundamentales a considerar, que dividen a las noticias falsas desde la visión política, son los que plantea Andrade (EC CRDPIC 2020a): el de las fake news y el de las false news. Las primeras nos conducirán a un "hackeo" de la democracia y la otra, al "hackeo" de la ciudadanía. En este sentido, se hace fundamental contar con sistemas de prevención y detección de noticias falsas, ya que no solo afectan a los individuos, sino que provocan daños severos a la democracia de una sociedad. Donde no haya información verdadera, o no exista la capacidad de comprobarla, entrará la información falsa. A partir de ella, una persona tomará sus decisiones de forma que se afecte la confianza pública y se debilite la democracia. En este contexto, al convertirse el individuo en un replicador de noticias falsas, se llega incluso a extremos en que los medios de comunicación vuelven sus portavoces, lo que causa un grave daño a la colectividad.

Una de las primeras consecuencias negativas de las noticias falsas y de la posverdad para el ejercicio del periodismo es la pérdida de credibilidad. Ante ello, varios autores 
dicen que los medios de comunicación deben hacer mejor su trabajo, y luchar en contra de cualquier interés que quiera deslegitimar y deshumanizar la profesión; es un esfuerzo que tienen y deben hacer los periodistas para evitar que el público sea manipulado con falsas realidades (CIDH 2020).

Frente a esto, redes sociales como Facebook y Twitter, buscadores como Google y aplicaciones de mensajería en línea como WhatsApp "se han dado cuenta de que la falta de fiabilidad en los contenidos que difunden es una amenaza a su propia existencia" (López-Borrull, Vives-Gràcia y Badell 2018, 1349), ya que estos medios se convierten en un megáfono que difunde rumores sin contrastación y pierden credibilidad e incluso interés comercial.

Otro de los efectos es el alto impacto y la incidencia en temas medulares de la sociedad merced a la utilización, principalmente, de algoritmos que distribuyen el contenido más relevante para cada usuario. Con esto, logran que la información que se muestra a cada uno esté condicionada y filtrada, de manera que se atenta contra los derechos de la comunicación. Esto ocurre gracias a que, en las redes sociales, altamente utilizadas por la población, el flujo informativo

se actualiza constantemente no solo por relevancia para el usuario sino también de acuerdo al alcance e interacciones que tiene el posteo, validando una noticia solo por su nivel de difusión. Por otro lado, los distintos intereses políticos, partidarios, o simplemente una confusión se vuelven motivos para que de una manera más frecuente se viralice un contenido engañoso. (IFJ 2018, 104)

Los efectos nocivos en personas u organizaciones tras la publicación de una fake news pueden ceñirse a diversos ámbitos, desde el personal hasta el económico, ya que tiene una capacidad movilizadora en la dirección a la cual el autor de esa fake news quiere que se muevan los destinatarios de la falsa información mediante la emocionalidad de los consumidores (Estudio de Comunicación y Servimedia 2017).

De igual manera, las noticias falsas han provocado algunos efectos positivos como abrir el debate acerca del rol de los medios frente a la verificación de la información, lo que ha provocado un fuerte crecimiento del fact-checking y otras herramientas similares (Fernández-García 2017).

\section{Discusión y conclusiones}

La difusión indiscriminada de noticias falsas comporta una problemática en la que entra en juego la función que deben cumplir los profesionales de la comunicación. Es el deber de estos mantener su lugar de reconocimiento y autoridad en el manejo de la información, a pesar de que manipulen datos provenientes de medios y redes sociales sin un contacto directo con la fuente (Catalina-García, Sousa y Silva 2019). 
Uno de los graves problemas que causa la desinformación es la proliferación de rumores, que en el entorno de emergencia sanitaria causan angustia y desesperación entre la población. Es aquí donde se precisa un entorno social en que el Estado blinde a la comunicación oficial y dificulte la producción de noticias falsas y la proliferación de la desinformación, mediante una comunicación transparente y precisa, con mensajes claros y detallados acerca de la forma de prevención y cuidado. Mucho mejor si estos son difundidos a través de voceros oficiales en distintas ramas profesionales: comunidad científica, autoridades con responsabilidades acordes al tema sanitario, y organizaciones de la sociedad civil con una línea discursiva alineada y coherente, para compartir certezas con la ciudadanía y apaciguar la angustia propia de la situación.

En los ámbitos de la información política y de la comunicación estratégica, es preocupante que las redes sociales sean el campo estratégico para atacar al adversario mediante la creación de rumores que se propagan como noticias falsas. Caso similar sucede con la información falsa que circula en redes sociales con relación a la emergencia sanitaria, y que pone en riesgo la vida de las personas.

Como se evidencia, la información es y ha sido usada como un arma en una escala sin precedentes. Esto se debe a que precisamente los avances tecnológicos y comunicacionales de la sociedad de la información han facilitado la fabricación y manipulación de contenido, que, al ser difundido por las redes sociales, amplifica de forma dramática las mentiras generadas por los Estados, por los políticos populistas y por las corporaciones deshonestas, entre población que carece de criterio para consumir esos contenidos y valorarlos (Unesco 2018).

Precisamente asistimos a lo que Catalina-García, Sousa y Silva (2019) miran como la consecuencia más perversa de este fenómeno: la sociedad no está preparada para un reconocimiento rápido de las fake news, pero aún más preocupante es que la propia sociedad esté mal informada y comparta información que siempre tiene que ser parte de su forma de ver y comprender el mundo.

Es indispensable construir un sistema de educación que permita la identificación de noticias falsas, aquellas que se construyen de una forma simple para causar impacto inmediato y curiosidad, con la suficiente urgencia para ser compartidas, especialmente por los grupos de mensajería que la persona disponga. De esta forma se concientizará sobre el peligro de su viralización, así como sobre los riesgos a los que se expone una sociedad.

La pandemia produjo un punto de inflexión para la humanidad. Es posible que volvamos a una "relativa normalidad"; sin embargo, nunca volveremos a ser los mismos. Ante nuestro asombro, hemos visto el desarrollo potente y vertiginoso de la tecnología $\mathrm{y}$, a través de ella, de las plataformas digitales.

El combate a la desinformación y las noticias falsas debe enfocarse desde la educación; no basta únicamente la mirada desde la comunicación, tomando en cuenta - 
como se ha expresado a lo largo de este trabajo- que la mayoría de las personas utiliza las redes sociales como fuente principal de información. Así, surge una pregunta: ¿cuál es la forma de combatir la desinformación y las noticias falsas? (Yépez, en EC CRDPIC 2020a). Una de las respuestas está en la alfabetización digital, una deuda de nuestro sistema educativo, político y social, y que se convierte en una necesidad latente a tomar en cuenta dentro de los debates y planteamientos de lo digital. Es momento de investigar y ejecutar planes de alfabetización digital desde otra perspectiva, y dejar de pensar que al hablar de plataformas digitales únicamente entran en juego las redes sociales.

El fenómeno de las noticias falsas termina por minar los espacios de diversidad del discurso y el concepto mismo de pluralidad. Desde la clasificación de los distintos sectores de la sociedad en estancos (por la lógica distributiva asociada a intereses generada por los algoritmos con que funcionan las redes sociales), hasta el ocultamiento deliberado de información de acuerdo a intereses particulares, la sociedad sufre una continua pérdida de acceso a espacios de discusión pública y exposición a la expresión de la diversidad cultural y de pensamiento, lo que prefigura un mundo atomizado en el que se agudicen conflictos que acaban favoreciendo a discursos radicales e intolerantes.

\section{Referencias}

Amorós, Marc. 2019. Fake news, la verdad de las noticias falsas. Barcelona: Plataforma.

Bolter, Jay David, y Richard Grusin. 2000. Remediation. Understanding New Media. Cambridge, US: MIT Press.

Britos, Christian, y Miguel Auzoberría. 2019. De cómo nos miran a cómo nos vemos: Fake news, posverdad y desinformación en Santa Cruz. Salta, AR: Academia.

Burgos, Julián. 2019. Fake news: Desmontando la objetividad. Un acercamiento crítico a las noticias falsas desde la teoría de Lippmann. Manizales, CO: Universidad de Manizales.

Casero-Ripollés, Andreu. 2012. "Más allá de los diarios: El consumo de noticias de los jóvenes en la era digital". Comunicar 39: 151-8. https://doi.org/10.3916/C39-2012-03-05.

Catalina-García, Beatriz, Jorge Sousa, y Li-Chang Cristina Silva. 2019. "Consumo de noticias y percepción de fake news entre estudiantes de Comunicación de Brasil, España y Portugal". Revista de Comunicación 18 (2): 93-115. https://doi.org/10.26441/RC18.2-2019-A5.

CIDH. 2019. Informe especial de la situación de libertad de expresión en Ecuador. Quito: OEA.

-. 2020. "Resolución N. ${ }^{\circ}$ 1/2020. Pandemia y derechos humanos en las Américas". Consejo de Derechos Humanos. 10 de abril. https://bit.ly/3bUwxmP.

Confirmado. 2019. "Perfiles de Opinión: 86 \% considera que los grandes medios ocultaron la verdad durante las movilizaciones". Confirmado. 23 de diciembre. https://bit.ly/3yBV8GQ. 
Del Fresno, Miguel. 2018. “Posverdad y desinformación: Guía para perplejos”. El País. 16 de marzo. https://bit.ly/3wzyDRa.

EC CRDPIC. 2020a. "Foro virtual Infodemia: Desinformación en crisis sanitaria: Memorias". Consejo de Regulación, Desarrollo y Promoción de la Información y Comunicación. 16 de diciembre. https://bit.ly/3yFKChZ.

—. 2020b. "Conferencia magistral Desinformación viral: Las noticias en la pandemia: Memorias". Consejo de Regulación, Desarrollo y Promoción de la Información y Comunicación. 16 de diciembre. https://bit.ly/3hYHcRz.

-. 2020c. "Conferencia magistral Ciberespacio, desinformación y periodismo activo: Memorias". Consejo de Regulación, Desarrollo y Promoción de la Información y Comunicación. 16 de diciembre. https://bit.ly/3fiw3sL.

—. 2020d. "Ciclo de conferencias Innovación modelos de negocio para medios de comunicación: Memorias". Consejo de Regulación, Desarrollo y Promoción de la Información y Comunicación. 16 de diciembre. https://bit.ly/3fHSiHL.

-. 2020e. "Memorias: Ciclo virtual - Seguridad para periodistas en situaciones de riesgo". Consejo de Regulación, Desarrollo y Promoción de la Información y Comunicación. 16 de diciembre de 2020. https://drive.google.com/file/d/1lve4DgDcmpmvIFGDjQcG4ZjBSjo3jScG/view

Estudio de Comunicación y Servimedia. 2017. Influencia de las noticias falsas en la opinión pública. Madrid: Estudio de Comunicación.

Fernández-García, Nuria. 2017. “Fake news’: Una oportunidad para la alfabetización mediática”. Nueva Sociedad 269. https://bit.ly/3fhp8Ai.

Freidenberg, Flavia. 2004. Los medios de comunicación de masas: ¿también son actores? Salamanca, ES: Universidad de Salamanca.

Gehrke, Mirjam, Nelsy Lizarazo, Patricia Noboa, David Olmos, y Oliver Pieper. 2016. "Panorama de los medios en Ecuador: Sistema informativo y actores implicados". Deutsche Welle. https://bit.ly/3bOuxg3.

IFJ. 2018. ¿Qué son las fake news?: Guía para combatir la desinformación en la era de la posverdad. Bruselas: IFJ. https://bit.ly/2T7EsGT.

López-Borrull, Alexandre, Josep Vives-Gràcia, y Joan-Isidre Badell. 2018. "Fake news, ¿amenaza u oportunidad para los profesionales de la información y la documentación?”. Profesional de la Información 27 (6): 1346-56. https://doi.org/10.3145/epi.2018.nov.17.

Mayoral, Javier, Sonia Parratt, y Monserrat Morata. 2019. “Desinformación, manipulación y credibilidad periodísticas: Una perspectiva histórica”. Historia y Comunicación Social 242: 395-409. https://doi.org/10.5209/hics.66267.

Murolo, Leonardo. 2019. La posverdad es mentira. Un aporte conceptual sobre fake news y periodismo. Madrid: Gedisa. 
Newman, Nic et al. 2017. Digital News Report. Oxford, GB: Oxford University Press.

OPS. 2021. "Entender la infodemia y la desinformación en la lucha contra el COVID-19”. Organización Panamericana de la Salud. Accedido 24 de mayo. https://bit.ly/3fIJzoB.

Pichincha Comunicaciones. 2020. "Sintonía en medios de comunicación cayó en un 50 \% debido a su baja credibilidad”. Pichincha Comunicaciones. 23 de enero. https://bit.ly/3bT26xu.

Primicias. 2020. "Primera muerte por coronavirus en Ecuador y los casos confirmados suben a 23". Primicias. 13 de marzo. https://bit.ly/3fkASC7.

Rincón, Omar. 2013. Narrativas mediáticas. Barcelona: Gedisa.

Tusa, Fernanda, y María Belén Durán. 2019. “La era de la desinformación y de las noticias falsas en el ambiente político ecuatoriano de transición: Un análisis de caso”. PerDebate 3: 18-41. https://doi.org/10.18272/pd.v3i1.1550.

Unesco. 2018. Periodismo, “noticias falsas” y desinformación. París: Unesco. https://bit.ly/3fiLb9K. 